Louisiana State University

LSU Digital Commons

Faculty Publications

Department of Physics \& Astronomy

10-1-2006

\title{
The CASTER Black Hole Finder Probe
}

\author{
M. L. McConnell \\ University of New Hampshire Durham \\ P. F. Bloser \\ University of New Hampshire Durham \\ G. L. Case \\ Louisiana State University \\ M. L. Cherry \\ Louisiana State University \\ J. Cravens \\ Southwest Research Institute
}

See next page for additional authors

Follow this and additional works at: https://digitalcommons.Isu.edu/physics_astronomy_pubs

\section{Recommended Citation}

McConnell, M., Bloser, P., Case, G., Cherry, M., Cravens, J., Guzik, T., Hurley, K., Kippen, R., Macri, J., Miller, R., Paciesas, W., Ryan, J., Schaefer, B., Stacy, J., Vestrand, W., \& Wefel, J. (2006). The CASTER Black Hole Finder Probe. New Astronomy Reviews, 50 (7-8), 633-636. https://doi.org/10.1016/j.newar.2006.06.042

This Article is brought to you for free and open access by the Department of Physics \& Astronomy at LSU Digital Commons. It has been accepted for inclusion in Faculty Publications by an authorized administrator of LSU Digital Commons. For more information, please contact ir@lsu.edu. 


\section{Authors}

M. L. McConnell, P. F. Bloser, G. L. Case, M. L. Cherry, J. Cravens, T. G. Guzik, K. Hurley, R. M. Kippen, J. R. Macri, R. S. Miller, W. Paciesas, J. M. Ryan, B. Schaefer, J. G. Stacy, W. T. Vestrand, and J. P. Wefel 
Louisiana State University

LSU Digital Commons

Faculty Publications

Department of Physics \& Astronomy

5-19-2006

\title{
The CASTER black hole finder probe
}

\author{
M. L. McConnell \\ University of New Hampshire Durham \\ P. F. Bloser \\ University of New Hampshire Durham \\ G. L. Case \\ Louisiana State University \\ M. L. Cherry \\ Louisiana State University \\ J. Cravens \\ Southwest Research Institute
}

See next page for additional authors

Follow this and additional works at: https://digitalcommons.Isu.edu/physics_astronomy_pubs

\section{Recommended Citation}

McConnell, M., Bloser, P., Case, G., Cherry, M., Cravens, J., Guzik, T., Hurley, K., Kippen, R., MacRi, J., Miller, R., Paciesas, W., Ryan, J., Schaefer, B., Stacy, J., Vestrand, W., \& Wefel, J. (2006). The CASTER black hole finder probe. AIP Conference Proceedings, 836, 696-699. https://doi.org/10.1063/1.2207980

This Conference Proceeding is brought to you for free and open access by the Department of Physics \& Astronomy at LSU Digital Commons. It has been accepted for inclusion in Faculty Publications by an authorized administrator of LSU Digital Commons. For more information, please contact ir@lsu.edu. 


\section{Authors}

M. L. McConnell, P. F. Bloser, G. L. Case, M. L. Cherry, J. Cravens, T. G. Guzik, K. Hurley, R. M. Kippen, J. R. MacRi, R. S. Miller, W. Paciesas, J. M. Ryan, B. Schaefer, J. G. Stacy, W. T. Vestrand, and J. P. Wefel 
University of New Hampshire

University of New Hampshire Scholars' Repository

Space Science Center

Institute for the Study of Earth, Oceans, and

Space (EOS)

2006

\title{
The CASTER Black Hole Finder Probe
}

\author{
Mark L. McConnell \\ University of New Hampshire - Main Campus, mark.mcconnell@unh.edu \\ Peter F. Bloser \\ University of New Hampshire, Peter.Bloser@unh.edu \\ G L. Case \\ Louisiana State University - Baton Rouge \\ M L. Cherry \\ Louisiana State University - Baton Rouge \\ J Cravens \\ Southwest Research Institute
}

See next page for additional authors

Follow this and additional works at: https://scholars.unh.edu/ssc

Part of the Astrophysics and Astronomy Commons

\section{Recommended Citation}

The CASTER Black Hole Finder Probe McConnell, M. L. and Bloser, P. F. and Case, G. L. and Cherry, M. L. and Cravens, J. and Guzik, T. G. and Hurley, K. and Kippen, R. M. and Macri, J. R. and Miller, R. S. and Paciesas, W. and Ryan, J. M. and Schaefer, B. and Stacy, J. G. and Vestrand, W. T. and Wefel, J. P., AIP Conference Proceedings, 836, 696-699 (2006), DOI:http://dx.doi.org/10.1063/1.2207980

This Conference Proceeding is brought to you for free and open access by the Institute for the Study of Earth, Oceans, and Space (EOS) at University of New Hampshire Scholars' Repository. It has been accepted for inclusion in Space Science Center by an authorized administrator of University of New Hampshire Scholars' Repository. For more information, please contact Scholarly.Communication@unh.edu. 


\section{Authors}

Mark L. McConnell, Peter F. Bloser, G L. Case, M L. Cherry, J Cravens, T G. Guzik, K Hurley, R M. Kippen, John R. Macri, R S. Miller, W Paciesas, James M. Ryan, B Schaefer, J G. Stacy, W T. Vestrand, and J P. Wefel 


\section{AIP $\mid$ Proceedings}

\section{The CASTER Black Hole Finder Probe}

M. L. McConnell, P. F. Bloser, G. L. Case, M. L. Cherry, J. Cravens, T. G. Guzik, K. Hurley,

R. M. Kippen, J. R. Macri, R. S. Miller, W. Paciesas, J. M. Ryan, B. Schaefer, J. G. Stacy,

W. T. Vestrand, and J. P. Wefel

Citation: AIP Conference Proceedings 836, 696 (2006); doi: 10.1063/1.2207980

View online: http://dx.doi.org/10.1063/1.2207980

View Table of Contents: http://scitation.aip.org/content/aip/proceeding/aipcp/836?ver=pdfcov

Published by the AIP Publishing

\section{Articles you may be interested in}

The Formation of Supermassive Black Holes in the First Galaxies

AIP Conf. Proc. 1294, 246 (2010); 10.1063/1.3518861

Search for Primordial Black Holes with SGARFACE

AIP Conf. Proc. 1085, 701 (2008); 10.1063/1.3076773

"Black Star" or Astrophysical Black Hole?

AIP Conf. Proc. 968, 426 (2008); 10.1063/1.2840449

Probing AGN Broad Line Regions with LAT Observations of FSRQs

AIP Conf. Proc. 921, 375 (2007); 10.1063/1.2757359

GLAST and GRBs: Probing Photon Propagation over cosmological distances

AIP Conf. Proc. 836, 692 (2006); 10.1063/1.2207979 


\title{
The CASTER Black Hole Finder Probe
}

\author{
M. L. McConnell ${ }^{*}$, P. F. Bloser*, G. L. Case ${ }^{\dagger, * *}$, M. L. Cherry ${ }^{\dagger}$, J. Cravens ${ }^{\ddagger}$, \\ T. G. Guzik ${ }^{\dagger}$, K. Hurley ${ }^{\S}$, R. M. Kippen ${ }^{\mathbb{I}}$, J. R. Macri*, R. S. Miller", W. \\ Paciesas $^{\|}$, J. M. Ryan*, B. Schaefer ${ }^{\dagger}$, J. G. Stacy ${ }^{\dagger, * *}$, W. T. Vestrand ${ }^{\mathbb{I}}$ and J. \\ P. Wefel ${ }^{\dagger}$ \\ * Space Science Center, University of New Hampshire, Durham, NH 03824 \\ ${ }^{\dagger}$ Department of Physics and Astronomy, Louisiana State University, Baton Rouge, LA 70803 \\ ${ }^{* *}$ Department of Physics, Southern University, Baton Rouge, LA 70813 \\ ${ }^{\ddagger}$ Department of Space Science, Southwest Research Institute, San Antonio, TX 78228 \\ ${ }^{\S}$ Space Sciences Laboratory, University of California, Berkeley, CA 94720 \\ ${ }^{\mathbb{L}}$ Los Alamos National Laboratory, Los Alamos, NM 87545 \\ ${ }^{\|}$Department of Physics, University of Alabama, Huntsville, AL 35899
}

\begin{abstract}
The primary scientific mission of the Black Hole Finder Probe (BHFP), part of the NASA Beyond Einstein program, is to survey the local Universe for black holes over a wide range of mass and accretion rate. One approach to such a survey is a hard X-ray coded-aperture imaging mission operating in the 10-600 keV energy band. The development of new inorganic scintillator materials provides improved performance that is well suited to the BHFP science requirements. Detection planes formed with these materials coupled with a new generation of readout devices represent a major advancement in the performance capabilities of scintillator-based gamma cameras. Here, we discuss the Coded Aperture Survey Telescope for Energetic Radiation (CASTER), a concept that represents a BHFP based on the use of the latest scintillator technology.
\end{abstract}

Keywords: X-ray instrumentation, gamma-ray instrumentation, X-ray sources, gamma-ray sources, black holes

PACS: $95.55 . \mathrm{Ka}$, 98.70.Qy, 98.70.Rz, 97.60.Lf, 97.80.Jp, 98.54.Cm

\section{INTRODUCTION}

NASA's Beyond Einstein Program [1] defines a sequence of space missions for exploring the Universe. One aspect of this program is a series of three Einstein Probe missions that would complement the facility-class Einstein Great Observatories (LISA and Con$\mathrm{X})$. One of the three Einstein Probe missions defined by the Beyond Einstein roadmap is the Black Hole Finder Probe (BHFP). The goal of the BHFP will be to carry out an all-sky census of accreting black holes. It is generally agreed that a hard X-ray coded mask imager covering the 10-600 keV energy band would be an effective tool for achieving this goal. One concept for the BHFP mission, known as EXIST (the Energetic X-ray Imaging Survey Telescope), has been under development for several years [24]. Here we offer an alternative concept, one that is similar to EXIST, but based on different detection technologies. We refer to our design concept as the Coded Aperture Survey Telescope for Energetic Radiation (CASTER) [5, 6]. CASTER is designed to employ several new experimental techniques using standard detector technologies, such as inorganic scintillators, wavelength-shifting fibers and photomultiplier tubes (PMTs), all of which have laboratory and space flight heritage. The development of 
a new inorganic scintillator material, lanthanum bromide $\left(\mathrm{LaBr}_{3}\right)$, provides improved performance that is well suited to the BHFP science requirements [7, 8]. With $\mathrm{LaBr}_{3}$, we now have the prospect of scintillators with energy resolution and stopping power on par with room-temperature semiconductors (such as CZT), but with far less cost. In addition, scintillator technology offers a practical means to extend the effective energy range beyond $511 \mathrm{keV}$. We therefore are exploring the implications, benefits and penalties, both practical and scientific, of using inorganic scintillators as the detector technology of a coded aperture imaging BHFP.

\section{THE CASTER CONCEPT}

The current concept for CASTER (similar to that of EXIST) envisions an array of 16 separate coded aperture telescope modules with overlapping fields-of-view. Each telescope would have a detection area of $64 \mathrm{~cm} \times 64 \mathrm{~cm}$, providing for a total detection area of $6.6 \mathrm{~m}^{2}$. The distinguishing feature of the CASTER concept is that the photon detection plane for each coded aperture telescope will be fabricated using traditional scintillator technologies. $\mathrm{LaBr}_{3}$ offers the properties of high stopping efficiency, high light output, good linearity, significantly improved energy resolution, fast response, and (potentially) low cost. The measured energy resolution of $2.6 \%$ FWHM at $662 \mathrm{keV}$ is comparable to the energy resolution of $3 \%$ at $662 \mathrm{keV}$ for off-the-shelf spectroscopy grade CZT. The fluorescent decay time $(\sim 25 \mathrm{~ns})$ is much faster than more traditional scintillator materials, thus assuring superior performance in high count-rate situations and in anticoincidence timing. In addition, as is the case with other inorganic scintillators, $\mathrm{LaBr}_{3}$ offers the possibility of fabricating relatively thick detectors to improve the detection efficiency at higher energies.

As part of a NASA-funded concept study, we have identified two detection plane configurations that warrant further study. Both configurations satisfy the basic criteria of the BHFP mission and provide an attractive low cost, low power option.

Anger camera modules, formed with multiple light sensors viewing a layer of scintillation material, are widely used for a variety of applications $[9,10]$. The interaction location is determined for each detected photon from the relative signals recorded for each PMT in the array. The spatial resolution of a gamma camera depends on geometrical factors such as the scintillator thickness, its size and the number and density of the light sensors in the array. Statistical and optical factors, such as scintillation yield, surface reflectivity, spectral match and photoelectron yield are also important. Current medical imaging technologies already achieve spatial resolutions of $\sim 1.5-2.0 \mathrm{~mm}$, a level of resolution that may be sufficient for the CASTER design. New gamma cameras employing the combination of higher light yield scintillator material $\left(\mathrm{LaBr}_{3}\right)$ and a higher density of light sensors, (e.g., multi-anode photomultiplier tubes - MAPMTs) are likely to provide even better spatial resolution capabilities. With proper calibration and analysis of the multiple PMT signals, the achievable energy threshold and spectroscopic performance of these Anger cameras should be similar to that achieved using single PMT spectrometers.

In addition to providing the location in the $x$ - and $y$-dimensions, the extent of the distribution of scintillation signals within the sensor plane provides a measure of the $z-$ 


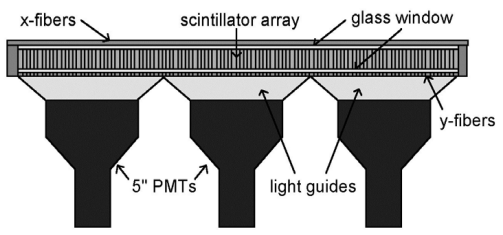

FIGURE 1. One possible imager design consisting of a pixellated scintillator array read out by wavelength shifting fibers. The large area PMTs are used for measuring total energy deposit.

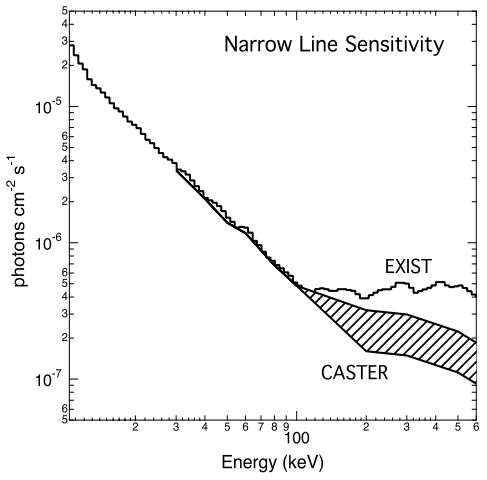

FIGURE 2. The estimated narrow line sensitivity for CASTER as compared to published sensitivity of EXIST ( $5 \sigma$ sensitivity, one-year exposure). The hatched area represents a range of possible sensitivity values for CASTER depending on the assumptions for the background scaling.

coordinate or depth of the interaction. Light from scintillations nearer the sensor plane is shared among fewer sensors than light from scintillations farther from the sensor plane. Anger cameras with a higher density of readout sensors will have improved ability to measure the $z$ coordinate. Multi-hit events would be identified and the interaction site locations measured in those cases where spatial resolution is better than the mean free path of the scattered photons.

A second approach, also adapted from medical imaging applications, is analogous to the design of solid state strip detectors [11]. In this case, one layer of wavelength-shifting fibers is laid in the $x$-direction across the top of a scintillator and a second layer of fibers is laid in the $y$-direction across the bottom. The light emitted by the fibers is read out at one end of each fiber by a set of MAPMTs. The crossed fiber layers measure the $x$ - and $y$ - position using the center of gravity of the light in the two fiber arrays, and the depth by using the signal distribution across the fiber arrays. Only a small fraction of the light is absorbed, reemitted, and trapped in the fibers, however. The energy measurement, therefore, is performed by a set of large area PMTs viewing the scintillator through the bottom fiber layer. This approach offers the possibility to provide a significant reduction in the power requirements by reducing the number of electronics channels as compared to a pixellated or Anger camera detector geometry. At lower energies, where the light output is reduced, the number of photoelectrons per fiber will become too small for the desired detection efficiency. In order to overcome the limitations of this approach at low energies, segmented scintillator arrays may be used (as in Fig. 1). The segmented nature of such arrays restricts the lateral spreading of the light within the scintillator. Preliminary testing of this concept has recently been conducted at LSU [12]. These tests are continuing with the goal of more fully evaluating the energy resolution and spatial resolution that can be achieved using this approach. 
One of the potential advantages of using inorganic scintillation crystals is that it will be much easier to construct thicker detection planes, thus providing improved photon sensitivity at higher energies. The source detection sensitivity will depend not only on the photon detection sensitivity, but also on the mask thickness and, most importantly, on the instrument background. This background is currently being studied using both Monte Carlo simulations and experimental measurements in particle beams. In the meantime, we have estimated the potential improvement in source sensitivity by appropriate scaling of the published sensitivity for EXIST [4]. At lower energies the background is dominated by the cosmic diffuse radiation, so the background will scale as detector area. At higher energies, internal background begins to play a role and so the background will scale roughly as detector volume. The crossover energy for the two different scalings is about $300 \mathrm{keV}$. Fig. 2 shows the narrow line sensitivity for CASTER based on these assumptions for background scaling. The EXIST sensitivity is based on $5 \mathrm{~mm}$ of CZT and a $5 \mathrm{~mm}$ thick (tungsten) coded mask. The CASTER sensitivity is based on $2 \mathrm{~cm}$ of $\mathrm{LaBr}_{3}$ and a $1 \mathrm{~cm}$ thick (tungsten) coded mask. The range of sensitivity values for CASTER at the higher energies corresponds to the range of background values derived from scaling by area (lowest levels) and scaling by volume (highest levels). Regardless of the precise nature of the background scaling, it is clear that the CASTER design has the potential for significant improvement in sensitivity at these highest energies.

The improved high energy sensitivity offered by the CASTER design directly translates into a greater scientific return. Of particular interest to the GRB community will be the more detailed high energy spectra of GRBs that would be measured by CASTER.

\section{ACKNOWLEDGMENTS}

The CASTER mission concept study has been supported by NASA grant NNG04GH78G. Some of this work is also supported at UNH by NASA grant NNG05WC26G and at LSU by US Dept. of Energy NNSA Cooperative Agreement DE-FC52-04-NA25683.

\section{REFERENCES}

1. White, N., Adv. Space Res. 35, 96 (2005).

2. Grindlay, J., et al., in GAMMA 2001, edited by S.Ritz, N. Gehrels \& C.R. Shrader, AIP Conf. Proc. 587, AIP, New York, 2001, pp. 899-908.

3. Grindlay, J. E., Proc. SPIE 4851, 331 (2002).

4. Grindlay, J., et al., in Gamma-Ray Burst and Afterglow Astronomy 2001, edited by G.R. Ricker \& R.K. Vanderspek, AIP Conf. Proc. 662, AIP, New York, 2003, pp. 477-480.

5. McConnell, M. L., et al., Proc. SPIE 5488, 944 (2004)

6. McConnell, M. L., et al., Proc. SPIE 5898, 1 (2005).

7. van Loef, E. V. D., et al., Appl. Phys. Lett. 79, 1573 (2001).

8. Shah, K. S., et al., IEEE Trans. Nucl. Sci. 50, 2410 (2003).

9. Anger, H. O., Rev. Sci. Instrum. 29, 27 (1958).

10. Macovski, A., Medical Imaging Systems, Prentice Hall, New York, 1983.

11. Matthews, K. L., et al., IEEE Trans. Nucl. Sci. 48, 1397 (2001).

12. Case, G. L., et al., Proc. SPIE 5898, 144 (2005). 